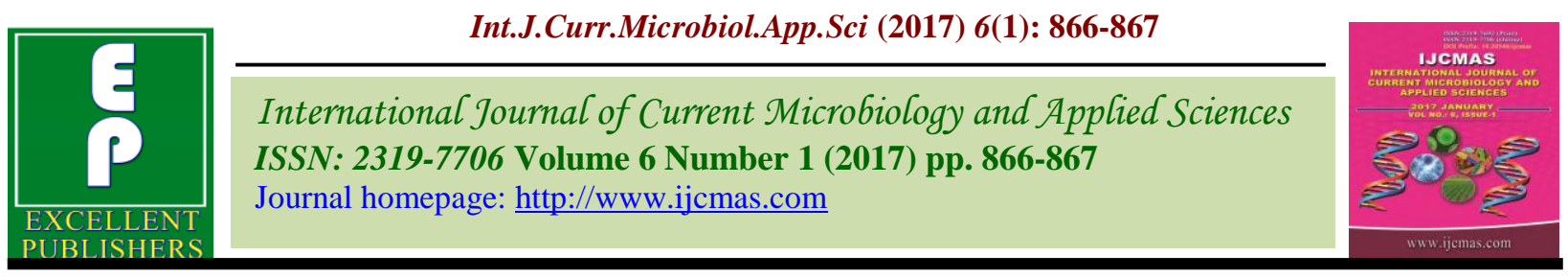

Letter to Editor

http://dx.doi.org/10.20546/ijcmas.2017.601.102

\title{
Research: A Tool from Imagination to Innovation
}

\author{
Vinai Kumar* \\ Plant Tissue Culture Lab, Dept. of Botany, Patna University, Patna Bihar \\ Research Scholar, Tissue Culture Lab., Dept. of Botany, Patna University, Patna \\ *Corresponding author
}

\section{Imagination}

Imagination is the first stepping stone towards innovation. People imagine a future and then start to work towards making them that dream come true. It forms the very basic foundation of creativity. Every one of us is born with the natural ability to imagine things, to dream and fantasize. But most people are afraid to share that imagination to others and that ultimately stops them from implementing it on the others hands. The creative individuals are bold, social and share their dreams with others. They have ability to harness imagination to creative ideas and have capacity to utilise this into commercially feasible innovation.

Imagination and creativity are central theme for research and innovation. Creativity requires risk taking. The more one experiments better are the chances of getting the right picture and have great chances to getting more information which are valuable to form a hypothesis. According to Merriam Webster, innovation is an invention useful only to the inventor unless it is offered to the public. If invention improves some products, process or services for the public, then that invention transforms into an innovation, which can be big or small.

\section{Research}

Research means re-search/to search again. The basic purpose of research is to discover answer to the questions through the application of scientific procedures. Each research study has its own specific purpose, but one can broadly categorise research objectives i.e. exploratory, formulatory, descriptive, diagnostic and hypothesis testing. The basic type of research includes descriptive vs. analytical, applied vs. fundamental, quantitative vs. qualitative, conceptual vs. empirical.

Therefore it is a scientific and systematic search for pertinent information on a specific topic. It is both art and science where careful investigations are done to bring out new facts. It is done for the purpose of discovering and explaining new knowledge, collection of information about subject, interpretation of facts and revision of accepted theories in light of new facts. That's why it is defined as search for knowledge or any systematic investigation to establish facts. It contributes to generalizable knowledge. The main aim of research is to find out truth which is hidden and which has not been discovered yet, though each research study has its own specific purpose. Thus research is to face the 
challenges in solving the unsolved problems i.e. concern over practical problems initiates research. The primary purpose for applied research (as opposed to basic research) is discovering, interpreting, and the development of methods and systems for the advancement of human knowledge on a wide variety of scientific matters of our world and universe. Research can use the scientific method, but need not do so. Scientific research relies on the application of the scientific method, a harnessing of curiosity. This research provides scientific information and theories for the explanation of nature and the properties of the world around us. It makes practical applications possible. The scientific research is funded by public authorities, charitable organisation and private groups including many companies.

Thus the journey from imagination to innovation is totally dependent on the research worker. The success of research work to a greater extent depends upon the qualities of researcher, which includes scientific frame of mind, possessing high degree of imagination power, able to grasp and visualise the intangible aspects, posses unlimited patience and inexhaustible perseverance, have good power to grasp the significance of things quickly and should be very clear in his concept along with thinking power. Addition specific qualities are knowledge of subject, knowledge of technique of research and personal taste in the study.

So researcher generates an innovation as exploiting new ideas leading to the creation of a new product, process or service. It is not just the invention of a new idea that is important, but it is a actually" bringing it to market", putting into practice and exploiting it in a manner that leads to new products, services or systems that add value or improve quality. It possibly involves technological transformation and management restructuring. It means exploiting new technology and employing out-of-the-box thinking to generate new value and to bring about significant changes in society. This century has been full of innovation. New technology, new products, new services, whole new industries etc. The presence of genius (guide) for shaping this (imagination, innovation and research) into right direction for fruitful result is must. Thus research is the chief out come from imagination to innovation, so the best research is one that indicates all the above mentioned qualities. That's why imagination plus innovation is equal to the research. The inevitability of research is to verify and test important facts, to analyse an event or process or phenomenon to identify the cause and effect relationship.To develop new scientific tools, concepts and theories to solve and understand scientific and nonscientific problems. To find solutions to scientific, nonscientific and social problems. To overcome or solve the problems occurring in our every day life. To equip researchers with research methodology essential for pursuing research degrees Ph.D. (Doctor of Philosophy), M.Phil. (Masters of Philosophy) and research at the undergraduate and postgraduate levels. To enable researchers in writing various research reports, thesis, dissertation, research papers, articles, essays. This is digital era now a days explore of information technology and software based applications are solving most of the problems accurately in very little time. Therefore they are the cheap tools for the researchers in the laboratories throughout the world rapidly gaining automatic control over the matters. 